\title{
ЕВРОПЕЙСКАЯ ИНТЕГРАЦИЯ: НОВЫЙ АСПЕКТ ИССЛЕДОВАНИЯ
}

Сидоров А.А. Конъюнктура еврозоны: Формирование и динамика. М.: ИНИЬН РАН, 2Ф19. 194 с.

Монография А.А. Сидорова не имеет аналогов в современной российской литературе, но при этом выступает продолжением давно сложившегося направления макроэкономических исследований. В экономической науке, как отечественной (М.И. Туган-Барановский, Н.Д. Кондратьев), так и зарубежной (К. Рогофф, Б. Айхенгрин), целая плеяда учёных, в том числе нобелевских лауреатов (Й. Шумпетер, С. Кузнец), развивала теорию экономической общехозяйственной и товарной конъюнктуры. При этом в фокус анализа представляемой монографии попал мало исследованный аспект экономической конъюнктуры - результат «развития процесса воспроизводства в масштабе экономики интеграционного объединения» при глубокой экономической интеграции (с. 161).

Такая степень интеграции пока существует только в рамках еврозоны Европейского Союза (ЕС), в состав которой входит 19 стран, и проявляется в динамике экономического роста и условиях реализации продукции совокупности стран, а не отдельных членов. Вместе с тем в теории экономической конъюнктуры уже появился новый раздел - конъюнктура интеграционного объединения. В перспективе вполне можно ожидать расширения объектов исследования за счёт углубления интеграции других интеграционных группировок.

Общехозяйственная конъюнктура не является лишь «арифметической суммой свойств составляющих её товарных конъюнктур», так же как и свойства конъюнктуры интеграционного объединения «нельзя считать арифметической суммой свойств конъюнктур стран-членов» (с. 13). В конечном счёте «в региональной социальноэкономической среде конкурентоспособность зависит от синергетического эффекта» [Орешкин, Хомутов 2011: 3], что будет характерно и для еврозоны.

С точки зрения доминирующих представлений о специфике хозяйствования ЕС основной тезис монографии контр-интуитивен. Представленная в работе обширная статистика доказывает, что, хотя его государства-члены причисляются к постиндустриальным, состояние их экономики и общехозяйственная конъюнктура определяются уровнем развития и производительностью труда в обрабатывающей промышленности. Именно она «оказывает наиболее сильное влияние на генерацию циклических колебаний» (с. 66).

Монография ценна не только с теоретической, но и с практической точки зрения. Значительный интерес представляет раздел, где проанализированы сложности, связанные с экономической конъюнктурой, которые могут возникнуть у региональных объединений в процессе углубления интеграции и её перехода на более высокие стадии. В числе фундаментальных проблем, от решения которых зависит жизнеспособность еврозоны, автор выделяет заложенную с момента её создания и ключевую, на его взгляд, структурную разнородность, о чём писал ещё Дж. Стиглиц [Stiglitz 2016: 124144]. С названной проблемой автор связывает и отсутствие в рамках исследуемого объединения оптимальной валютной зоны. 
Страны еврозоны не способны противостоять внешним шокам не только в силу исключительной открытости экономики, но и в силу отсутствия национальных инструментов денежно-кредитной политики, возможности девальвировать национальную валюту в целях повышения ценовой конкурентоспособности своих товаров (с. 124).

В числе проблем еврозоны автор также выделяет процессы регулирования рынка труда в связи с демографическими проблемами и сложившейся системой социального обеспечения (особенно в странах Юга). Отмечено отставание стран еврозоны в развитии высокотехнологичных отраслей и утрата ими позиций на мировых рынках из-за внешних (конкуренции со стороны развивающихся стран) и внутренних проблем (запаздывания с проведением реформ рынка труда) (с. 131). В целом неспособность Старой Европы осушествить структурные реформы налогообложения, социальной системы, рынка труда (что усугубляется старением населения), констатировалось и в более ранних работах [Сидорова 2010: 118]. Наряду с ними проблемы бюджетного дефицита и государственного долга, также характерные стран Юга еврозоны, автор связывает с деградацией обрабатывающей промышленности (с. 135-136).

Остановлюсь на оценке в книге перспектив развития еврозоны под влиянием внешних условий. В их ряду автор рассматривает возможную экономическую интеграцию ЕС и США. Обе названные экономики находятся под давлением конкуренции со стороны крупных развивающихся стран. Ответом на этот вызов могло бы стать соглашение о свободной торговле между ЕС и США - Трансатлантическое торговое и инвестиционное партнёрство (ТТИП). Автор полагает, что откладывание переговоров по созданию такой экономической макрозоны после избрания американского президента Д. Трампа ТТИП выгодно скорее еврозоне. У неё будет больше времени для реформ, укрепления собственных позиций на рынке, что позволит выстраивать отношения с Вашингтоном с более устойчивых позиций.
Ссылаясь на официальные документы Европейской комиссии, автор отмечает, что в контексте роста конкуренции с Китаем, $\mathrm{EC}$ «предпринял шаги по ужесточению законодательства в области защиты внутреннего рынка» (с. 142). Между тем практическая деятельность Брюсселя зачастую не совпадает с его официальными заявлениями [Клинова 2019: 127-128]. В рамках самого ТТИП, в случае его реанимирования, конкуренция между ЕС и США ещё более обострится на фоне существующих взаимных претензий в рамках ВТО (с. 146).

Важное место в монографии отведено сопоставлению динамики и проблем общехозяйственной конъюнктуры еврозоны с другими центрами мирового хозяйства, прежде всего Соединёнными Штатами, что позволяет выделить её отличительные черты. Наиболее существенные из выделенных автором особенностей общехозяйственной конъюнктуры еврозоны являются её глубокое ухудшение по сравнению с США при меньшем сокращении занятости в конце первого десятилетия XXI века; наличие двух волн спада; наличие ядра, формирующего общехозяйственную конъюнктуру, а также стран-локомотивов; становление конъюнктуры объединения, а не ориентация экономической динамики на страну-лидера, как, например, в НАФТА (с. 158-159).

Практический интерес представляет заключительный параграф книги, посвящённый анализу опыта еврозоны применительно к Евразийскому экономическому союзу (ЕАЭС) и перспектив формирования его конъюнктуры. Автор обоснованно считает применимым опыт функционирования единственного полноценного валютного союза - еврозоны - к ЕАЭС, который с его российскоцентричной моделью экономической интеграции осуществляет переход к общему рынку.

Проведя сравнительный анализ основных экономических условий, существовавших при создании еврозоны в 1999 г. и ЕАЭС в 2016 году, автор приходит к выводу, что по всем критериям евразийское объединение гораздо более разнородно, чем еврозона на момент её образования. В еврозоне нет тако- 
го явно выраженного экономического лидера по уровню ВВП и экспорта, как в ЕАЭС, хотя Германия выделяется на общем фоне (с. 153). Представляется целесообразным, опираясь на стартовые условия (наличие выраженной доминантной страны в объединении), сравнивать ЕАЭС с НАФТА, а не с еврозоной: у США в 2016 (как и в 2004) было 87,8\% совокупного ВВП НАФТА; у России в ЕАЭС - 86,4\% (с. 114, 153).

Кроме того, для экономики государствчленов интеграционного объединения важно не «номинальное закрепление и продвижение стадий интеграции» (с. 157), а фактическое состояние сотрудничества взаимной торговли и инвестиций, которое в ЕАЭС находится на более низком уровне, чем в еврозоне и в НАФТА. Причём НАФТА находится на более низкой стадии интеграции, чем ЕАЭС. В рамках последнего не наблюдается тенденции к синхронизации динамики общехозяйственной конъюнктуры государств-членов, важнейшим условием чего является «интенсивное торговоэкономическое сотрудничество внутри группировки» (с. 159).

Пример еврозоны показывает, что спешить с созданием валютного союза (и особенно с принятием в него стран на основе политических соображений) не стоит.
Вместе с тем «согласование макроэкономической политики представляет собой важный задел на будущее интеграции и говорит о серьёзности намерений участников Договора о Евразийском экономическом союзе» (с. 156).

Представленный труд побуждает высказать всего два пожелания. Bo-nервых, в одну из таблиц с классификацией стран еврозоны по степени наукоёмкости (с. 82) включены всего тринадцать стран, входивших в неё на 2012 год. Было бы целесообразно её дополнить, включив весь нынешний состав валютного блока в количестве 19 членов. Bo-вторых, остаются сомнения по поводу правомерности отнесения мер количественного смягчения к нетрадиционным на фоне указания, что такие меры применялись в США и Японии (с. 103).

В целом книга свидетельствует о том, что экономическая конъюнктура - актуальное, живое, прикладное направление экономической науки. Автору можно пожелать в будущем провести более углублённый анализ применения концепции циклов роста для исследования экономической конъюнктуры в развивающихся странах.

\section{Валерий Орешкин доктор экономических наук, профессор}

\section{Список литературь।}

Клинова М.B. Национализм vs европеизм в преддверии выборов в Европарламент // Научноаналитический вестник Института Европы РАН. 2019. № 2. С. 125-130.

Орешкин В.А., Хомутов А.О. Пути повышения конкурентоспособности кластерных образований // Российский внешнеэкономический вестник. 2011. № 12. С. 3-9.

Сидорова Е.A. Будущее ЕС после расширения: обновление сценария // Мировая экономика и международные отношения. 2010. № 6. С. 117-127.

Stiglitz J. The Euro and Its Threat to the Future of Europe. London: Allen Lane. XXIX, 2016. 454 p.

\section{References}

Klinova M.V. (2019). Natsionalizm protiv yevropeizma v preddverii vyborov v Yevroparlament [Nationalism vs Europeanism before the Elections to the European Parliament]. Nauchno-analiticheskiy vestnik Instituta Yevropy RAN. No. 2. P. 125-130.

Oreshkin V.A., Khomutov A.O. (2011). Puti povysheniya konkurentosposobnosti klasternykh obrazovaniy [Ways to increase the competitiveness of cluster entities]. Rossiyskiy vneshneekonomicheskiy vestnik. No. 12. P. 3-9.

Sidorova E.A. (2010). Budushcheye ES posle rasshireniya: obnovleniye stsenariya [The future of the EU after enlargement: scenario update]. Mirovaya ekonomika i mezhdunarodnyye otnosheniya. No. 6. P. 117-127.

Stiglitz J. (2016). The Euro and Its Threat to the Future of Europe. London: Allen Lane. 454 p. 